\title{
Surgical Management of Perianal Giant Condyloma Acuminatum (Buschke-Löwenstein Tumor)
}

Report of Three Cases

\author{
Giorgio De Toma $^{a}$ Giuseppe Cavallaro ${ }^{a}$ Andrea Bitonti ${ }^{b} \quad$ Andrea Polistena $^{a}$ \\ Maria Giuseppina Onesti ${ }^{\text {b }}$ Nicolò Scuderi ${ }^{b}$ \\ a Department of Surgery 'Pietro Valdoni', Policlinico Umberto I, University 'La Sapienza' and ' Department of \\ Cutaneous-Venereal Diseases and Plastic Reconstructive Surgery, Policlinico Umberto I, University 'La Sapienza', \\ Rome, Italy
}

\section{Key Words}

Buschke-Löwenstein tumor · Giant condyloma acuminatum

\begin{abstract}
Giant condyloma acuminatum (GCA) is a slow-growing, large, cauliflower-like tumor located in the anogenital region. This tumor has a locally destructive behavior, a high recurrence rate and occasional transformation to squamous cell carcinoma. Risk factors include anoreceptive intercourse, HIV and immunosuppression. There is no general agreement on the choice of treatment for this tumor. Wide radical excision with plastic reconstruction of skin defects seems to be the best treatment, while adjuvant therapies, such as radiotherapy and immunotherapy, may achieve good results, but their effectiveness is still uncertain. Loop colostomy, considered mandatory by several authors in order to minimize wound contamination risk, does not appear to be necessary (except in cases of anal canal involvement beyond the dentate line) if a combination of bowel cleansing, non-fiber diet and loperamide can be administered. The authors report 3 cases of perianal GCA treated by radical local excision and reconstruction by S-plasty grafts, without performing loop colostomy.

Copyright $\odot 2006$ S. Karger AG, Basel
\end{abstract}

\section{Introduction}

Giant condyloma acuminatum (GCA) is a slow-growing, large, cauliflower-like tumor with a locally destructive behavior that typically appears in the anogenital region. It was originally described as a penile lesion by Buschke in 1896 and Löwenstein in 1925 [1]. The first description of anorectal GCA was by Dawson et al. [2] in 1965. GCA is a rare lesion tending to present in the fifth decade with a 2.7:1 male:female ratio. For patients $<50$ years, this ratio is increased to 3.5:1 [3]. Risk factors include anoreceptive intercourse, HIV and immunosuppression.

Although clinically malignant, its histology is benign, without propensity for distant metastases. Despite this, GCA has a high rate of local recurrence, and occasionally malignant transformation to squamous cell carcinoma [4]. A number of authors therefore consider GCA to be a regional variant of verrucous carcinoma, while others consider it a distinct and separate entity $[5,6]$. There is no general agreement on the choice of treatment for this tumor, due to its localization close to important structures (such as the anal sphincter), and to its biologic behavior which is still not completely known. Most authors recommend early control of local disease by radical

\section{KARGER}

Fax +41613061234 E-Mail karger@karger.ch www.karger.com
Dr. Giuseppe Cavallaro

Department of Surgery 'P. Valdoni', Policlinico Umberto I

Viale del Policlinico, IT-00161 Rome (Italy)

Tel./Fax + 390649972197

E-Mail giuseppe.cavallaro@uniroma1.it 


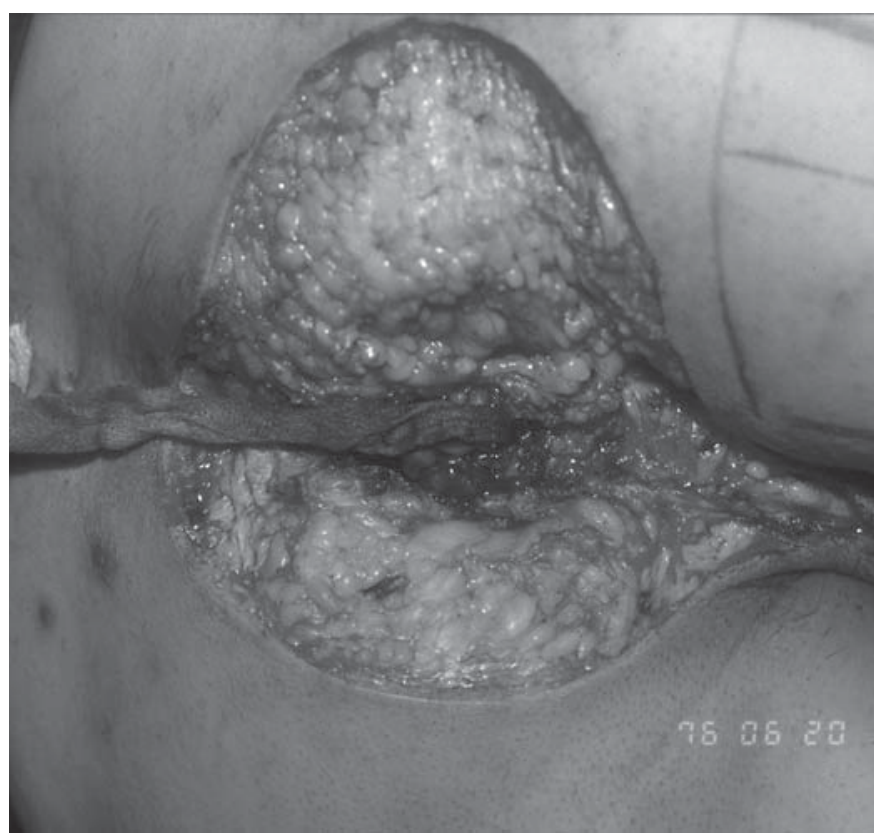

Fig. 1. Extended excision of the tumor.

excision, and eventual abdominoperineal resection in cases of recurrence, pelvic invasion or malignant transformation $[4,5,7]$. Many authors recommend performing temporary loop colostomy before surgical excision, to avoid the risk of fecal contamination of the wounds, but this argument is still being debated; in fact, GCA rarely involves the anal canal, and adequate diet and eventual loperamide administration can achieve good results with less discomfort.

The authors report 3 cases of perianal GCA treated by radical local excision and reconstruction by S-plasty grafts, without performing loop colostomy.

\section{Case Reports}

Case 1

A 46-year-old heterosexual man, HIV-negative, was admitted to our department for a lesion located at the level of the perianal region that had been present for about 1 year, with progressive size increase and ulceration. At physical examination this vegetative, ulcerated lesion presented as a cauliflower-like tumor measuring $8 \mathrm{~cm}$ in length and $6 \mathrm{~cm}$ in diameter; it was stone hard and painful with touch.

He underwent surgical local excision with direct closure; histologic findings showed the presence of verrucous carcinoma. After systemic treatment with interferon ( 3 million IU), a pelvic CT scan showed an irregular parietal thickening of the posterior lat-

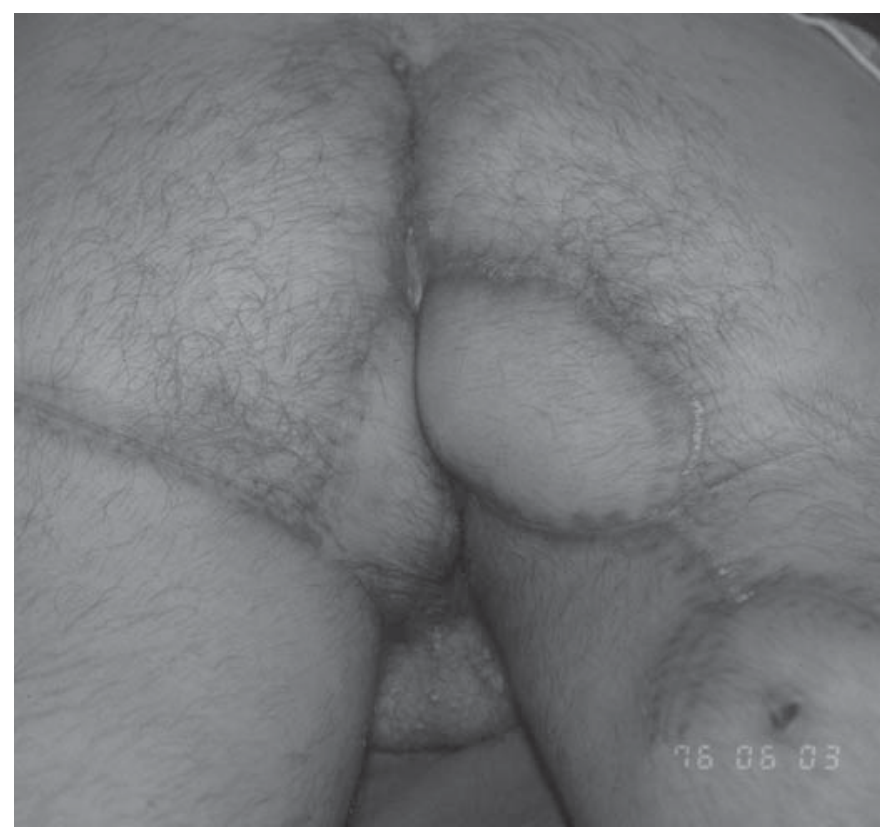

Fig. 2. Wound closure after the use of a posterior right leg flap and left gluteus flap.

eral left rectal edge and anal edge. The patient therefore underwent radiotherapy, but after only 11 cycles he had to suspend it because of local infection. After 6 months from the first surgical operation, because of the rapid growth of the lesion, the patient underwent another surgical excision (under general anesthesia) (fig. 1). The entire specimen was sent for histological examination to ensure clear margins and to evaluate the presence of foci of verrucous carcinoma. Skin defect reconstruction was performed with the use of a posterior right leg flap and left gluteus flap (fig. 2). To ensure good wound healing, without fecal contamination, a non-fiber diet and loperamide $(12 \mathrm{mg} /$ day $)$ were administered for 4 days postoperatively. Histologic findings showed the presence of a giant Buschke-Löwenstein condyloma, with no evidence of verrucous carcinoma. Human papilloma virus (HPV) analysis was performed by Southern blot hybridization, demonstrating the presence of HPV type 6. After 3 years the patient is doing well, without evidence of disease recurrence.

Case 2

A 40-year-old transsexual man, HIV-positive, was admitted to our department in March 2002 for GCA of the anal and perianal region. The patient was in treatment with a combination of antiretroviral drugs.

Dermatologic examination revealed a cauliflower-like tumor mass measuring $10 \times 12 \mathrm{~cm}$ involving the perianal region with pus drainage, foul smell and pain. After radical excision, the wound was covered with a mesh-skin graft and the patient had to stay in bed 5 days after grafting. HPV analysis was performed by Southern blot hybridization, demonstrating the presence of HPV types 6 and 11 . 


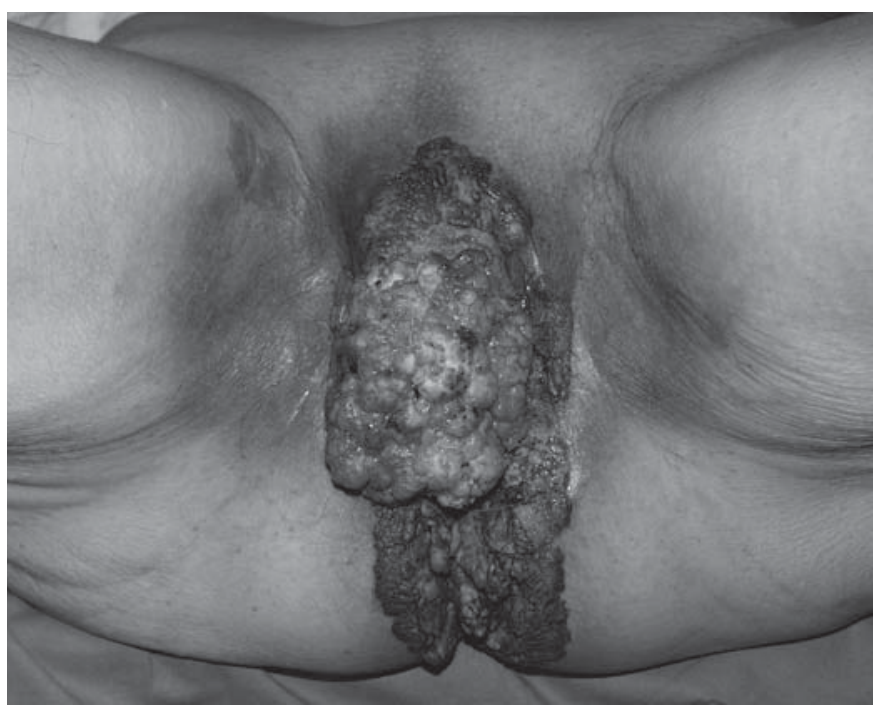

Fig. 3. Tumor propagation from the anal canal to the vulva.

On the 9th day after grafting, the patient was allowed to walk and a program of daily wound showering was started. Complete healing took about 3 weeks from the time of grafting. After 4 months he had recurrence and was treated with local resection. At the last visit in March 2005, the patient was doing well with no evidence of disease recurrence.

\section{Case 3}

A 65-year-old woman, multipara, HIV-negative, came to our department in June 2003, 22 years after the first appearance of lesions in the anal and perianal region because of anogenital bleeding.

Detailed examination showed propagation from the anal canal to the vulva measuring $20 \mathrm{~cm}$ in length and varying from 8 to $10 \mathrm{~cm}$ in diameter. The lesion gradually increased in size over time and the patient had pain, a foul smell and difficulty walking and sitting (fig. 3). The lesion was treated with a large surgical excision (fig. 4) and reconstruction using two gluteus transposition flaps and a Dufourmentel flap from the right leg was performed. HPV analysis was performed by Southern blot hybridization, demonstrating the presence of HPV types 6 and 11. After 2 years the patient is doing well but she has to be controlled every 6 months because of the high rate of recurrence.

In all 3 cases, fecal contamination was avoided by diet and loperamide $4 \mathrm{mg}$ three times daily.

\section{Discussion}

The incidence of perianal GCA has slightly increased during the last decade, but it can still be very difficult to distinguish GCA from ordinary condylomas or well-dif-

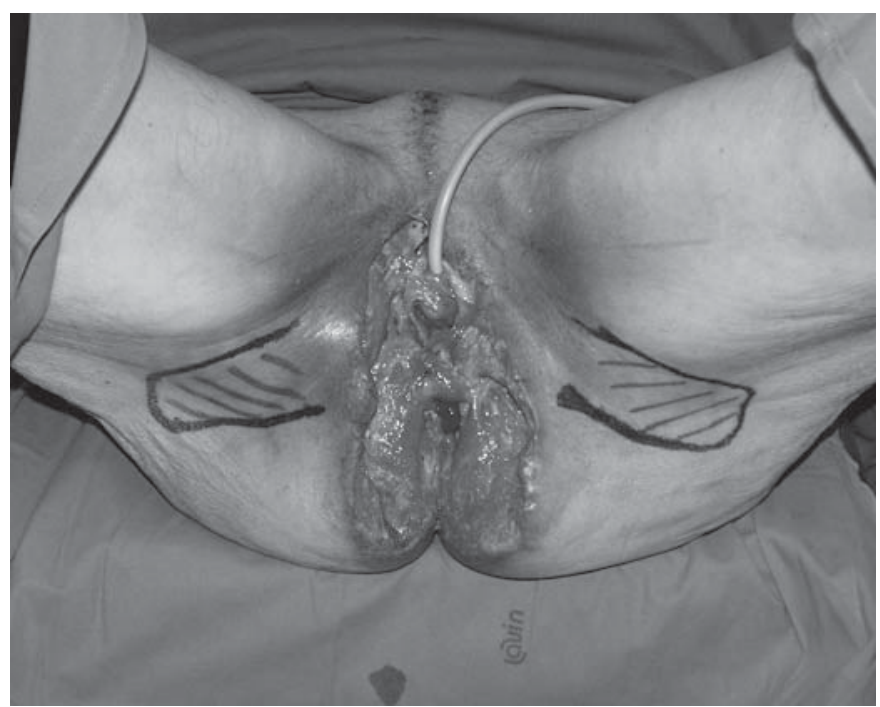

Fig. 4. A large surgical excision was performed before skin defect reconstruction.

ferentiated squamous cell carcinomas. There is probably a viral etiology (HPV subtypes 6-11 and 13-15) [8,9]. Clinically these lesions often present with similar findings, and can be distinguished by histological examination [10-12]. At histology, GCA differentiates from other lesions by its thick stratum corneum, marked papillary proliferation, and tendency to deep invasion, with displacement of the surrounding tissues [7]. These same features, seen also in verrucous carcinomas, led several authors not to recognize a distinction between verrucous carcinoma and Buschke-Löwenstein tumor [5]. However, GCA does not present histological evidence of malignancy, such as infiltration of basement membrane, lymphatic invasion, angioinvasion or distant metastases [13]. Despite this, GCA can coexist with verrucous carcinoma or squamous cell carcinoma in up to $50 \%$ of patients $[7,14]$.

There are still many problems concerning the management of Buschke-Löwenstein tumors because of the high recurrence rates (up to 70\%) [7] and the lack of adequate series of patients following the same procedure. It is now established that the topical application of podophyllin, even if gives good results on ordinary condyloma acuminatum, is not recommended in GCA for the lack of results $[2,5]$. The role of immunotherapy (based on the evidence of viral infection), with preparation of autologous vaccine, has been evaluated in the treatment of recurrent or extensive GCA, with very good results in small series of patients $[15,16]$. 
Interferon has also been used, via topical, intralesional or even systemic route [17]. Direct intratumoral interferon injection can achieve eradication in up to $45-60 \%$ of patients, but high recurrence rates are reported [18] Systemic administration of interferon can be performed in cases where lesions are too large to be treated with direct injection or with surgical excision with worse results $[17,18]$.

The use of radiotherapy is still controversial, because of the evidence of anaplastic transformation and extensive appearance of new condylomas after its use, and because of the lack of long-term results [19-21]. The role of systemic chemotherapy is not well defined because of paucity of data, and also topical chemotherapy with 5fluorouracil seems to give poor results in the case of GCA [7].

Surgery remains the method of choice to achieve local control of the disease, even after recurrence. Since conservative treatments (Mohs' microsurgery, cryosurgery or laser resection) do not allow good results in terms of disease control and recurrence, there are two recommended methods of radical treatment: radical local excision, with healing by secondary intention or eventual skin defect reconstruction by the use of mesh-skin grafts [22], S-plasty [23], split-thickness grafts [24], or other kinds of reconstructions $[25,26]$, and abdominoperineal resection, which should be performed in cases of tumor recurrence, pelvic invasion or malignant transformation.

There are two main problems concerning surgical treatment: (1) The high recurrence rate, both after radical local excision and abdominoperineal resection; for this, abdominoperineal resection is not recommended for primary treatment, except in the case of extensive bone or pelvic involvement. (2) The localization of the tumor: wound healing in the perianal area can be difficult because of the presence of feces, which can lead to contam- ination of the surgical site. For this, temporary loop colostomy is recommended by several authors, to avoid the risk of fecal contamination $[4,7,19]$.

Loop colostomy indeed creates patient discomfort, with limitation of daily activities (these patients are often young, with an average age of 30-40), and can present surgical complications. In the 3 reported cases, radical local excision was performed as primary treatment, with S-plasty reconstruction, with good wound healing, without graft infection or complications. Loop colostomy was not performed, but bowel cleansing with an osmotic laxative was performed preoperatively, and a combination of non-fiber diet and loperamide was administered postoperatively.

One patient had disease recurrence after 4 months and was treated with local resection without any complications. All the patients are doing well 1 year after surgery, with no evidence of disease recurrence and with no problems concerning fecal continence.

\section{Conclusions}

The optimal treatment for Buschke-Löwenstein tumor is still being debated because of the lack of a consistent series of patients. Despite this, at the moment, wide radical excision with plastic reconstruction of skin defects seems to be the best choice. Adjuvant therapies, such as radiotherapy and immunotherapy, may achieve good results, but their effectiveness is still uncertain. Loop colostomy, considered mandatory by several authors in order to minimize wound contamination risk, does not appear to be necessary (except in cases of anal canal involvement beyond the dentate line) if a combination of bowel cleansing, non-fiber diet and loperamide can be administered.

\section{References}

1 Buschke A, Löwenstein L: Über karzinomähnliche Condylomata acuminata des Penis. Klin Wochenschr 1925;4:1726-1728.

-2 Dawson DF, Duckworth SK, Bernhardt H, et al: Giant condyloma and verrucous carcinoma of the genital area. Arch Pathol 1965;79: 225-231.

3 Trombetta U, Place RJ: Giant condyloma acuminatum of the anorectum: trends in epidemiology and management. Dis Colon Rectum 2001;44:1878-1886.

\footnotetext{
-4 Creasman C, Haas PA, Fox TA Jr, Balazs M Malignant transformation of anorectal giant condyloma acuminatum (Buschke-Löwenstein tumor). Dis Colon Rectum 1989;32: 481-487.

5 Bogomoletz WV, Potet F, Molas G: Condylomata acuminate, giant condyloma acuminatum (Buschke-Löwenstein tumor) and verrucous squamous cell carcinoma of the perianal and anorectal region: a continuous precancerous spectrum? Histopathology 1985;9:155-169.
}

-6 Batta AG, Engen DE, Reiman HM, Winkelmann RK: Intravesical condyloma acuminatum with progression to verrucous carcinoma. Urology 1990;36:457-464.

7 Chu QD, Vezeridis MP, Libbey NP, Wanebo $\mathrm{HJ}$ : Giant condyloma acuminatum (BuschkeLöwenstein tumor) of the anorectal and perianal regions: analysis of 42 cases. Dis Colon Rectum 1994;37:950-957.

Treatment of Perianal

Eur Surg Res 2006;38:418-422 
8 Boshart N, zur Hausen H: Human papillomavirus in Buschke-Löwenstein tumors: physical state of the DANN and identification of a tandem duplication in the non-coding region of a human papillomavirus $6 \mathrm{sub}$ type. J Virol 1986;58:963-966.

-9 Lehn H, Ernst TM, Sauer G: Transcription of episomal papillomavirus DANN in human condylomata acuminata and Buschke-Löwenstein tumors. J Gen Virol 1984;65:20032010.

-10 Dianzani C, Bucci M, Pierangeli A, et al: Association of human papillomavirus type 11 with carcinoma of the penis. Urology 1998; 51:1046-1048.

11 Rubben A, Beaudenon S, Favre M, et al: Rearrangements of the upstream regulatory region of human papillomavirus type 6 can be found in both Buschke-Löwenstein tumours and in condylomata acuminata. J Gen Virol 1992;73:3147-3153.

-12 Castren K, Vahakangas K, Heikkinen E, Ranki A: Absence of p53 mutations in benign and pre-malignant male genital lesions with overexpressed $\mathrm{p} 53$ protein. Int J Cancer 1998;77:674-678.
13 Renzi A, Brusciano L, Giordano P, Rossetti G, Izzo D, Del Genio A: Busche-Löwenstein tumor. Successful treatment by surgical electrocautery excision alone: a case report. Chir Ital 2004;56:297-300.

14 Chao MWT, Gibbs P: Squamous cell carcinoma arising in a giant condyloma acuminatum (Buschke-Löwenstein tumor). Asian J Surg 2005;28:238-240.

15 Abcarian H, Smith D, Sharon N: The immunotherapy of anal condyloma acuminatum. Dis Colon Rectum 1976;19:237-244.

16 Eftaiha MS, Amshel AL, Shonberg IL, Batshon B: Giant and recurrent condyloma acuminatum appraisal of immunotherapy. Dis Colon Rectum 1982;25:136-138.

17 Trofatter KF: Interferon treatment of anogenital human papillomavirus-related disease. Dermatol Clin 1991;9:343-351.

18 Browder JF, Araujo OE, Myer NA, Flowers SP: The interferons and their use in condyloma acuminata. Ann Pharmacother 1992; 26:42-45.

19 Bertram P, Treutner KH, Rubben A, Hauptmann S, Schumpelick V: Invasive squamouscell carcinoma in giant anorectal condyloma (Buschke-Löwenstein tumor). Langenbecks Arch Chir 1995;380:115-118.

20 Jablonska S, Obalek S, Orth G, Breitburd F, Croissant O: Tumeur géante de BuschkeLöwenstein a 11PV 6 avec métastases dans la paroi abdominal. Ann Dermatol Vénéréol 1988;115:1201-1202.
21 Sobrado CW, Mester N, Nadalin W, Nahas SC, Bocchini SF, Habr-Gama A: Radiationinduced total regression of a highly recurrent giant perianal condyloma: report of a case. Dis Colon Rectum 2000;43:257-260.

22 Mestrovic T, Cavcic J, Martinac P, Turcic J, Zupancic B, Cavcic AM, Jelincic Z: Reconstruction of skin defects after radical excision of anorectal giant condyloma acuminatum: six cases. J Eur Acad Dermatol Venereol 2003;17:541-545.

23 Oh C, Albanese C: S-plasty for various anal lesions. Am J Surg 1992;10:606-608.

24 Bishara B, Eitan A, Barzilai A: Malignant transformation of perianal condyloma acuminatum. Harefuah 1991;121:230-231.

25 Uribe N, Millan M, Flores J, Asencio F, Diaz F, Ruiz del Castillo J: Excision and V-Y plasty reconstruction for giant condyloma acuminatum. Tech Coloproctol 2004;8:9-11.

26 Dolanc R, Kocher T, Langer I, Marti WR, Pierer G, Harder F: Malignant transformation of perianal Buschke-Löwenstein tumor. Extensive abdominoperineal rectum excision and reconstruction with transpelvic myocutaneous rectus abdominis muscle flap. Chirurg 2002;73:370-374. 